\title{
Comparison of Effects of Dobutamine and Ouabain on Left Ventricular Contraction and Relaxation in Closed-Chest Dogs
}

\author{
William C. Little, Anis Rassi, Jr., and Gregory L. Freeman* \\ Cardiology Section, Department of Medicine, Bowman Gray School of Medicine, Wake Forest University, Winston-Salem, \\ North Carolina 27103; and *Division of Cardiology, University of Texas Health Science Center, San Antonio, Texas 78284
}

\begin{abstract}
Because catecholamines and digitalis have different effects on the time course of myocardial intracellular calcium concentration, their effects on the time course of left ventricular contraction and relaxation may also be different. To study this question, dogs were instrumented to measure left ventricular pressure and determine left ventricular volume from three ultrasonic dimensions. After full recovery from the instrumentation, the effects of dobutamine $(2-10 \mu \mathrm{g} / \mathrm{kg})$, ouabain $(0.5 \mathrm{mg}$ i.v.) alone, and ouabain given after propanolol ( $2 \mathrm{mg} / \mathrm{kg}$ i.v.), or phentolamine (5 $\mathrm{mg}$ i.v.) and incremental doses of ouabain (0.25-0.75 $\mathrm{mg}$ i.v.) were assessed on different days. Left ventricular pressure and volume were varied by caval occlusions. Dobutamine significantly increased the slope of the left ventricular end-systolic pressure-volume relation $\left(E_{\max }\right)$ and the slope of the $d P / d t_{\max }$-end-diastolic volume relation $\left(d E / d t_{\max }\right)$, while significantly decreasing the time from end-diastole to end-systole $\left(t_{\max }\right)$ and the time constant $(T)$ of the isovolumic fall in left ventricular pressure. Ouabain also increased $E_{\max }$ and $d E / d t_{\max }$ but did not alter $t_{\max }$ or $T$. Dobutamine produced a greater increase in $d E / d t_{\max }$ than in $E_{\max }$, whereas ouabain produced similar increases in both. These effects of ouabain were not altered by pretreatment with propanolol or phentolamine.

We conclude that although dobutamine and ouabain are both positive inotropes that increase $E_{\max }$, dobutamine speeds the rate of left ventricular contraction $\left(t_{\max }\right)$ and relaxation $(T)$, whereas ouabain does not. These effects of ouabain and dobutamine on global parameters of left ventricular chamber performance mirror their influence on intracellular calcium availability. Furthermore, these observations are consistent with the predictions of the time-varying elastance model of the left ventricle and support its usefulness as a conceptual framework to understand and link events occurring during isovolumic contraction, end-systole, and isovolumic relaxation.
\end{abstract}

\footnotetext{
A preliminary report was presented at AFCR/ASCI/AAP national meeting, Washington, DC, May 1986.

Address reprint requests to William C. Little, M.D., Department of Medicine (Cardiology), Bowman Gray School of Medicine, Wake Forest University, $300 \mathrm{~S}$. Hawthorne Road, Winston-Salem, NC 27103.

Received for publication 2 September 1986 and in revised form 23 April 1987.
}

J. Clin. Invest.

(c) The American Society for Clinical Investigation, Inc.

0021-9738/87/09/0613/08 $\$ 2.00$

Volume 80, September 1987, 613-620

\section{Introduction}

Left ventricular (LV) ${ }^{1}$ systole can be divided into phases: isovolumic contraction, ejection, end-systole, and isovolumic relaxation (1). Indices have been developed that describe LV performance during each of these four phases. However, it has been difficult to provide a description of the LV that spans all four phases, unifying and relating the various measures of $\mathrm{LV}$ performance. One possibility is to consider that LV systolic pumping function can be described as a time-varying elastance (2-5). In this concept, the $\mathrm{LV}$ is considered to behave as an elastic structure that stiffens in a predictable manner during systole. The $\mathrm{LV}$ pressure, $P(t)$, at any time after the onset of contraction, $t$, is described by: $P(t)=E(t)\left[V(t)-V_{0}\right]$, where $E(t)$ is $\mathrm{LV}$ elastance at $t, V(t)$ the $\mathrm{LV}$ volume at $t$, and $V_{0}$ the minimum volume required for the $\mathrm{LV}$ to generate super-atmospheric pressure. LV elastance, $E(t)$, reaches a maximum value, $E_{\max }$, at time $t_{\max }$, which has been termed end-systole. $E_{\max }$, which is the slope of the end-systolic pressure $\left(P_{\mathrm{ES}}\right)$-volume $\left(V_{E S}\right)$ relation, is a measure of the global inotropic state of the LV and is relatively insensitive to changes in loading conditions in isolated canine hearts $(2,3,5-10)$, conscious dogs (11), and man $(12,13)$. Inotropic stimulation with catecholamines increases $E_{\max }$ and decreases $t_{\max }$, the time from enddiastole to end-systole (2-4).

In addition to the $P_{\mathrm{ES}}-V_{\mathrm{ES}}$ relation, the time-varying elastance model has other implications that suggest links between the four phases of systole. For example, the model suggests that the maximum rate of rise of $\mathrm{LV}$ pressure $\left(d P / d t_{\max }\right)$, normally occurring during isovolumic contraction, is linearly related to the $L V$ end-diastolic volume $\left(V_{\mathrm{ED}}\right)(3,4)$. The slope of this relation, $d E / d t_{\max }$, is also predicted to be sensitive to inotropic state and proportional to $E_{\max } / t_{\max }$, providing a link between events occurring during isovolumic contraction and at endsystole. Further consideration of the time-varying elastance hypothesis (Appendix) also suggests that the rate of LV pressure fall during isovolumic relaxation should be inversely proportional to $t_{\max }$. These predictions of the time-varying elastance model linking events occurring during isovolumic contraction $\left(d P / d t_{\max }-V_{\mathrm{ED}}\right.$ relation), at end-systole (the $P_{\mathrm{ES}}-V_{\mathrm{ES}}$ relation and $\left.t_{\max }\right)$, and during isovolumic relaxation $(T)$ suggest that this model may provide a unified description of $\mathrm{LV}$ performance throughout systole.

1. Abbreviations used in this paper: $d E / d t_{\max }$, slope of $d P / d t_{\max }$-end-diastolic volume relation; $d P / d t_{\max }$, maximum rate of rise of $P(t)$; ED, end-diastolic; $E_{\max }$, slope of end-systolic pressure-volume relation; $\mathrm{ES}$, end-systolic; $L V$, left ventricular; $P(t), L V$ pressure; $t_{\max }$, time from end-diastole to end-systole. 
The increase in LV elastance after electrical stimulation is a manifestation of the tension generated by the sarcomeres reflected through the complex geometry of the $\mathrm{LV}$ chamber $(14,15)$. Because the force of sarcomere contraction is directly related to amount of calcium available to the contractile proteins, the time course of LV systolic elastance should follow the time course of calcium availability, though lagging behind in time. Studies using the bioluminescent indicator aequorin suggest that catecholamines increase the peak amount of calcium available after electrical stimulation and also decrease the time required to achieve this peak $(13,16)$. The time course of calcium availability after catecholamine stimulation is qualitatively very similar to the effect of catecholamines on LV elastance (i.e., increasing $E_{\max }$ and decreasing $t_{\max }$ ). Digitalis, however, has a different effect on calcium availability. While the peak of calcium is increased, the time to reach this peak is unchanged. If the time course of $\mathrm{LV}$ elastance reflects calcium availability then digitalis glycosides should increase $E_{\max }$ but not alter $t_{\max }$. If this is correct, then the time-varying elastance hypothesis predicts that digitalis compounds should produce similar increases in $E_{\max }$ and $d E / d t_{\max }$ and should not alter the time course of the fall of LV pressure during isovolumic relaxation.

This study was undertaken to test these predictions by comparing the effects of dobutamine and ouabain (a digitalis glycoside) on the $P_{\mathrm{ES}}-V_{\mathrm{ES}}$ and $d P / d t_{\max }-V_{\mathrm{ED}}$ relations, $t_{\max }$, and the time constant of $L V$ relaxation.

\section{Methods}

Instrumentation. 16 healthy, adult mongrel dogs weighing $23 \pm 3 \mathrm{~kg}$ (mean \pm SD) were instrumented by a slight modification of a previously described technique $(4,17,18)$. A sterile left lateral thoracotomy was performed under anesthesia with halothane (1-2\%) after induction with xylene $(1 \mathrm{mg} / \mathrm{kg})$ and sodium thiopental $(6 \mathrm{mg} / \mathrm{kg})$. The pericardium was opened widely. A micromanometer pressure transducer (Konigsberg Instruments, Inc., Pasadena, CA) and a polyvinyl catheter for transducer calibration (inside diameter, $1.1 \mathrm{~mm}$ ) were inserted through the LV apex. Three pairs of ultrasonic crystals ( $5 \mathrm{MHz}$ ) were implanted in the endocardium of the LV to measure the anterior-posterior, septal-lateral, and base-apex (long-axis) dimensions. Bipolar pacing leads were sutured to the left atrial appendage. Hydraulic occluder cuffs were placed around the inferior and superior venae cavae.

Data collection. All studies were performed after full recovery from the thoracotomy (10-14 d) with the dogs lying on their right sides in a sling. The $L V$ catheter was connected to a pressure transducer (Statham P23DB) calibrated with a mercury manometer. The signal from the micromanometer was adjusted to match that of the catheter. The transit time of $5 \mathrm{MHz}$ sound between the crystal pairs was determined and converted to distance assuming a constant velocity of sound in blood of $1.55 \mathrm{~m} / \mathrm{ms}$. The first derivative of $\mathrm{LV}$ pressure $(d P / d t)$ was obtained by electronically differentiating the micromanometer signal using an analogue circuit with a linear frequency response to $>70 \mathrm{~Hz}$. The analog signals were recorded on an eightchannel oscilligraph (Beckman Instruments Inc., Fullerton, CA), digitized with an on-line analog-to-digital converter (Data Translation Devices, Marlboro, MA) at $200 \mathrm{~Hz}$, and stored on a floppy disk memory system utilizing a computer system (PDP 11/23, Digital Equipment Corp., Marlboro, MA).

Experimental protocol. To avoid the confounding influences of respiratory changes in intrathoracic pressure and variations in the level of autonomic tone, the dogs were sedated with fentanyl (0.03-0.06 $\mathrm{mg} / \mathrm{kg}$ i.v.) in combination with droperidol $(1.5-3.0 \mathrm{mg} / \mathrm{kg}$ i.v.), given $0.5 \mathrm{~h}$ after pretreatment with xylene $(1 \mathrm{mg} / \mathrm{kg}$ i.m.), and intubated. All data were recorded during 12-s periods while the dogs were apneic, with the glottis held open by the endotracheal tube (17). During each experiment the heart rate was kept constant by pacing from the atrium. Small amounts of atropine (0.2-1 mg i.v.) were administered as needed to prevent atrio-ventricular block in the animals that received ouabain.

In six dogs, the effect of dobutamine ( $10 \mu \mathrm{g} / \mathrm{kg}$ per min i.v.), ouabain ( $0.5 \mathrm{mg}$ i.v.), ouabain ( $0.5 \mathrm{mg}$ i.v.) after propanolol ( $2 \mathrm{mg} / \mathrm{kg}$ i.v.), and ouabain $(0.5 \mathrm{mg}$ i.v.) after phentolamine $(5 \mathrm{mg}$ i.v.) were assessed on different days. During each study, data were recorded during a steady-state, nonintervention period to obtain baseline values. The $P_{\mathrm{ES}}-V_{\mathrm{ES}}$ and $d P / d t_{\max }-V_{\mathrm{ED}}$ relations were then generated by sudden occlusion of the cavae. This caused a progressive fall in $\mathrm{LV}$ end-systolic pressure, volume, and $d P / d t_{\max }$ over a 12 -s recording period. Immediately after the recording period, the caval occlusion was released. After all parameters had returned to their baseline level, the caval occlusion was repeated. Then dobutamine was infused or ouabain given. The animal was allowed to equilibriate for $5 \mathrm{~min}$ (dobutamine infusion) or $10 \mathrm{~min}$ (ouabain), and then the measurements were repeated.

In four animals pretreated with atropine ( $2 \mathrm{mg}$ i.v.), the effects of incremental infusions of dobutamine $(0,2,4,6,8 \mathrm{~g} / \mathrm{kg}$ per $\mathrm{min})$ were assessed in a similar manner. Finally, in a separate group of six animals, the effects of ouabain $(0.25 \mathrm{mg})$ given every $5 \mathrm{~min}$ to produce total doses of $0.25,0.50$, and $0.75 \mathrm{mg}$ were assessed in a similar manner. Higher doses of ouabain could not be used because they produced junctional and ventricular dysrhythmias.

Data analysis. The stored digitized data were analyzed by computer algorithm $(11,17)$. Baseline hemodynamic values in each dog were obtained by averaging the data obtained during the 12-s steadystate, nonintervention recording periods. End-systole was defined as the time when the ratio of LV pressure to volume reached its maximum (19). End-diastole was defined as the peak of the $R$ wave of the electrocardiogram. The time from end-diastole to end-systole was defined as $t_{\max }$. End-ejection was defined as peak negative $d P / d t$. The LV volume $\left(V_{\mathrm{LV}}\right)$ was calculated as a modified general ellipsoid using the equation $V_{\mathrm{LV}}=(\pi / 6) D_{\mathrm{AP}} D_{\mathrm{SL}} D_{\mathrm{LA}}$, where $D_{\mathrm{AP}}=$ the anterior-posterior $\mathrm{LV}$ dimension, $D_{\mathrm{SL}}=$ the septal-lateral $\mathrm{LV}$ dimension, and $D_{\mathrm{LA}}=$ the long-axis LV dimension. Because this method of volume determination depends on dimensional measurements, it is important to assess its accuracy under the conditions used in this study (19). This method of volume calculation has been validated in our laboratory $(11,17,19$, 20,21 ) and is similar to that used by others (22), except that we determined endocardial dimensions directly. Thus, the subtraction of LV wall thickness or volume was not necessary. We $(11,17,18,20)$ and Olsen et al. (22) have found that this method gives a consistent measure of $\mathrm{LV}$ volume $(r>0.97$, standard error of estimate $<2 \mathrm{ml}$ ) despite changes in LV loading conditions and configuration produced by caval occlusions.

The time constant $(T)$ of the isovolumic fall in LV pressure was determined by fitting the steady-state data from end-ejection to the time that $\mathrm{LV}$ pressure had fallen to $10 \mathrm{mmHg}$ above the end-diastolic pressure to the equation: $P_{\mathrm{LV}}=P_{0} \mathrm{e}^{-t / T}+P_{\mathrm{B}}$, using BMDP program PAR (23), where $t$ is the time from end-ejection, and $P_{0}$ and $P_{\mathrm{B}}$ are constants determined by the data.

Only caval occlusions that produced a fall in LV systolic pressure of at least $30 \mathrm{mmHg}$, and that produced no extra systoles, were analyzed. The LV end-systolic pressure-volume data during the fall of LV pressure produced by the caval occlusions were fit to: $P_{\mathrm{ES}}=E_{\max }\left(V_{\mathrm{ES}}-V_{0}\right)$, using the linear least squares technique. The $\mathrm{LV} V_{\mathrm{ED}}$ and $d P / d t_{\max }$ were fit to $d P / d t_{\max }=\left(d E / d t_{\max }\right)\left(V_{\mathrm{ED}}-V_{0}\right)$, where $d E / d t_{\max }$ is the slope of the relation and $V_{0}$ is the volume intercept. In animal 2 , the ultrasonic dimension crystals malfunctioned before administration of ouabain, thus the effect of this intervention on the $P_{\mathrm{ES}}-V_{\mathrm{ES}}$ and $d P / d t_{\max }-V_{\mathrm{ED}}$ relations could not be determined in this animal.

Statistical methods. All results were summarized as the mean $\pm \mathrm{SD}$, and the level of significance was $P<0.05$. Dose-response curves were analyzed using a split-plot, repeated-measures analysis of variance. Multiple comparisons were performed by analysis of variance. Single 
intergroup comparisons were performed using paired $t$ tests or the Wilcoxon signed rank test (24).

Postmortem studies. At the conclusion of the experiments, the animals were sacrificed and the hearts were examined to confirm the proper positioning of the instrumentation.

\section{Results}

Typical analog recordings before and after the infusion of dobutamine and ouabain are shown in Fig. 1. An analog recording after the occlusion of the vena cava is shown in Fig. 2.

Effect of dobutamine. The infusion of dobutamine (10 $\mu \mathrm{g} / \mathrm{kg}$ per min) significantly increased $d P / d t_{\max }$, while decreasing $t_{\max }$, end-diastolic and end-systolic $\mathrm{LV}$ volumes, $\mathrm{LV}$ enddiastolic pressure, and $T$. Heart rate was kept constant during dobutamine infusion by atrial pacing at $138 \pm 24$ beats/min. The LV end-systolic pressure as well as $P_{0}$ and $P_{\mathrm{B}}$ were unchanged (Table I). $E_{\max }$ increased from $7.24 \pm 4.40$ to $13.61 \pm 5.80 \mathrm{mmHg} / \mathrm{ml}(P<0.05)$ in response to the infusion of $10 \mu \mathrm{g} / \mathrm{kg}$ per min of dobutamine, whereas the volume axis intercept of the $P_{\mathrm{ES}}-V_{\mathrm{ES}}$ relation was unchanged (Table II). Dobutamine also shifted the $d P / d t_{\max }-V_{\mathrm{ED}}$ relation to the left, increasing its slope, $d E / d t_{\max }$ from $63.0 \pm 20.4$ to $177.1 \pm 83.6$ $\mathrm{mmHg} / \mathrm{ml}$ per s $(P<0.05)$ without changing its volume intercept (Table III). The increase in $d E / d t_{\max }$ to $282 \pm 170 \%$ of control was greater than the increase in $E_{\max }$ to $184 \pm 57 \%$ of control $(P<0.05)$. These effects of dobutamine $(10 \mu \mathrm{g} / \mathrm{kg}$ per min) on the $d P / d t_{\max }-V_{\mathrm{ED}}$ and $P_{\mathrm{ES}}-V_{\mathrm{ES}}$ relations are similar to previous observations reported from our laboratory $(4,11)$. Similar dose-related effects on $E_{\max }, d E / d t_{\max }, t_{\max }$, and $T(P$ $<0.05)$ were seen with the incremental infusion of lower doses of dobutamine (Fig. 3). Of special note is the progressive fall in $t_{\max }$ and $T$ with incremental doses of dobutamine (Fig. 4).

Effect of ouabain. The administration of $0.5 \mathrm{mg}$ of ouabain increased $P_{\mathrm{ES}}$ from $100 \pm 14$ to $123 \pm 26 \mathrm{mmHg}(P<0.05)$

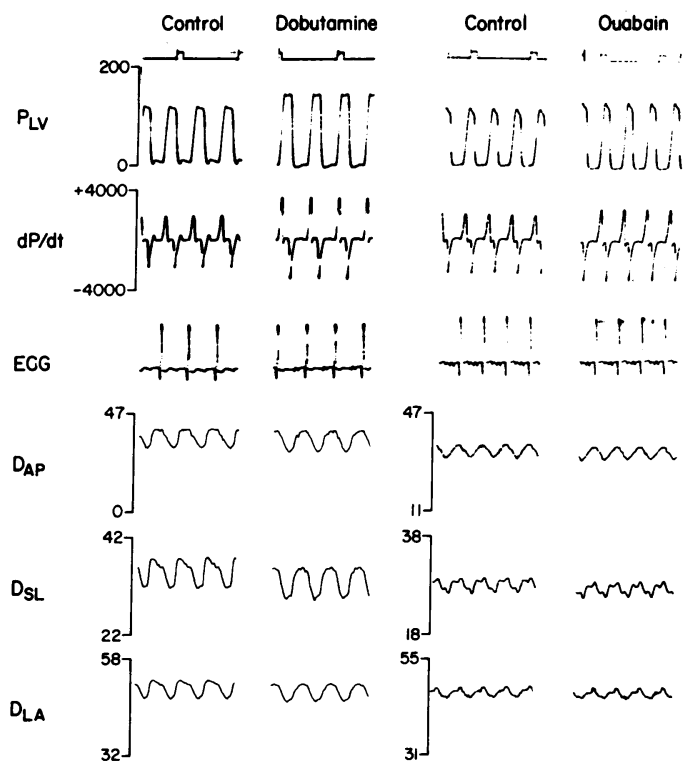

Figure 1. Analog recordings of left ventricular pressure $\left(P_{L V}\right)$, the time derivative of left ventricular pressure $(d P / d t)$, and the three left ventricular dimensions (anterior-posterior $\left[D_{A P}\right]$, septal-lateral $\left[D_{S L}\right]$, and long-axis $\left.\left[D_{L A}\right]\right)$ during control and dobutamine infusion (10 $\mu \mathrm{g} / \mathrm{kg}$ per $\mathrm{min})$ and after ouabain $(0.5 \mathrm{mg})$.

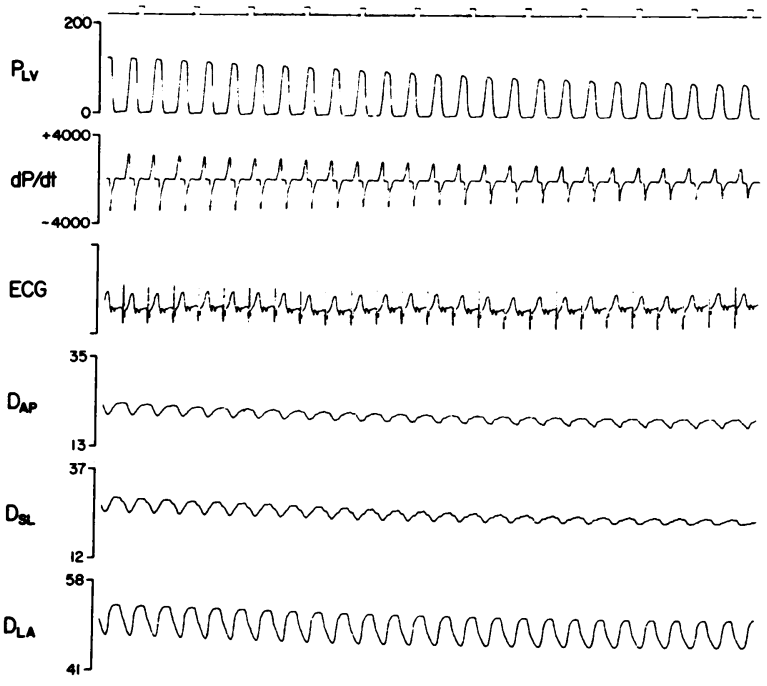

Figure 2. Analog recording after vena cava occlusion. Abbreviations are same as Fig. 1.

(Table I). A similar effect was seen after beta blockade but was attenuated after pretreatment with phentolamine. Ouabain significantly increased $d P / d t_{\max }$ from $2,098 \pm 87$ to $2,775 \pm 362$ $\mathrm{mmHg} / \mathrm{s}(P<0.05)$ but had no effect on $t_{\max }(178 \pm 22$ vs. $175 \pm 26 \mathrm{~ms})$ or $T(28.7 \pm 6.6$ vs. $29.9 \pm 6.4 \mathrm{~ms})$. Pretreatment with propanolol or phentolamine did not alter this effect. Ouabain shifted the $P_{\mathrm{ES}}-V_{\mathrm{ES}}$ relation to the left (Fig. 5) increasing the slope, $E_{\max }$ from $8.87 \pm 4.35$ to $9.99 \pm 4.81 \mathrm{mmHg} /$ $\mathrm{ml}(P<0.05)$ and decreasing $V_{0}$ from $13.30 \pm 6.43$ to $10.61 \pm 7.85 \mathrm{ml}$. This leftward shift results in a higher $P_{\mathrm{ES}}$ being associated with each $V_{\text {ES }}$. Ouabain had a similar effect on $E_{\max }, V_{0}$ after pretreatment with propanolol, but after the administration of phentolamine, $E_{\max }$ increased from $8.19 \pm 2.71$ to $11.71 \pm 4.11 \mathrm{mmHg} / \mathrm{ml}(P<0.05)$ without a change in $V_{0}$ $(11.23 \pm 5.45$ vs. $11.75 \pm 5.40 \mathrm{ml})$. Ouabain also shifted the $d P /$ $d t_{\max }-V_{\mathrm{ED}}$ relation to the left so that each $V_{\mathrm{ED}}$ was associated with a higher $d P / d t_{\max }$ (Fig. 4). The increases in the slope of this relation, $d E / d t_{\max }$, with ouabain (unblocked, betablocked, and after phentolamine) were similar to the increases in $E_{\max }(113 \pm 9,130 \pm 18,142 \pm 11 \%$ vs. $131 \pm 20,144 \pm 48$, $145 \pm 12 \%$ of control). Incremental doses of ouabain produced similar significant dose-related increases $(P<0.05)$ of $E_{\max }$ and $d E / d t_{\max }$, but did not alter $t_{\max }$ or $T$ (Fig. 6).

Comparison of dobutamine and ouabain. Both ouabain and dobutamine increased $E_{\max }$ and $d E / d t_{\max } \cdot d E / d t_{\max }$ increased by $120 \pm 109 \%$ more than $E_{\max }$ in response to dobutamine, but $d E / d t_{\max }$ increased by only $18 \pm 21 \%$ more than $E_{\max }$ in response to ouabain $(P<0.05)$. Dobutamine produced a $25 \pm 17-\mathrm{ms}$ greater decrease in $t_{\max }(P<0.05)$ than occurred with ouabain (i.e., $t_{\max }$ decreased $28.3 \pm 15.1 \mathrm{~ms}$ with dobutamine and only changed by $3.3 \pm 4.1 \mathrm{~ms}$ with ouabain). Similarly, dobutamine produced an 11.8 \pm 8 .1-ms greater decrease $(P<0.05)$ in $T$ than occurred with ouabain (i.e., $T$ decreased by $10.7 \pm 7.6 \mathrm{~ms}$ with dobutamine, and increased by $1.1 \pm 4.1$ $\mathrm{ms}$ in response to ouabain).

\section{Discussion}

This study demonstrates that although dobutamine and the digitalis glycoside, ouabain, are both positive inotropes that 
Table I. Effect of Dobutamine and Ouabain on Hemodynamic Parameters

\begin{tabular}{lcccccccc}
\hline & Control & Dobutamine & \multicolumn{1}{c}{ Control } & Ouabain & $\begin{array}{l}\text { Beta-blocked } \\
\text { control }\end{array}$ & $\begin{array}{l}\text { Ouabain after } \\
\text { beta blockade }\end{array}$ & $\begin{array}{l}\text { Phentolamine } \\
\text { control }\end{array}$ & $\begin{array}{l}\text { Ouabain after } \\
\text { phentolamine }\end{array}$ \\
\hline $\mathrm{HR}$ & $138 \pm 24$ & $138 \pm 24$ & $130 \pm 18$ & $130 \pm 18$ & $124 \pm 18$ & $124 \pm 18$ & $133 \pm 23$ & $133 \pm 23$ \\
$d P / d t_{\max }$ & $2,155 \pm 477$ & $3,200 \pm 902^{*}$ & $2,098 \pm 87$ & $2,775 \pm 362^{*}$ & $1,723 \pm 408^{*}$ & $2,382 \pm 530^{*}$ & $2,292 \pm 736$ & $2,876 \pm 953^{*}$ \\
$d P / d t_{\min }$ & $-2,231 \pm 562$ & $-2,487 \pm 799$ & $-2,039 \pm 363$ & $-2,450 \pm 578$ & $-1,733 \pm 265$ & $-2,509 \pm 481^{*}$ & $-2,093 \pm 546$ & $-2,514 \pm 684^{*}$ \\
$V_{\mathrm{ED}}$ & $38.8 \pm 14.4$ & $29.4 \pm 12.5^{*}$ & $33.3 \pm 11.9$ & $32.3 \pm 10.4$ & $34.9 \pm 11.1$ & $35.5 \pm 11.8$ & $29.9 \pm 12.3$ & $28.7 \pm 10.9$ \\
$V_{\mathrm{ES}}$ & $29.7 \pm 10.8$ & $21.2 \pm 8.9$ & $24.1 \pm 9.4$ & $23.8 \pm 8.6$ & $26.8 \pm 9.0$ & $26.6 \pm 9.6$ & $20.7 \pm 9.2$ & $19.5 \pm 7.3$ \\
$P_{\mathrm{ED}}$ & $5.8 \pm 5.4$ & $1.06 \pm 3.5^{*}$ & $2.9 \pm 2.6$ & $2.7 \pm 1.2$ & $5.8 \pm 2.5$ & $7.3 \pm 4.3$ & $4.8 \pm 4.0$ & $4.8 \pm 4.3$ \\
$P_{\mathrm{ES}}$ & $128 \pm 26$ & $115 \pm 28$ & $100 \pm 14$ & $123 \pm 26^{*}$ & $100 \pm 7.9$ & $139 \pm 8.3^{*}$ & $94 \pm 16$ & $107 \pm 17$ \\
$t_{\max }$ & $188 \pm 17$ & $160 \pm 23^{*}$ & $178 \pm 22$ & $175 \pm 26$ & $189 \pm 7$ & $188 \pm 15$ & $168 \pm 15$ & $163 \pm 19$ \\
$T$ & $37.4 \pm 11.0$ & $26.6 \pm 6.6^{*}$ & $28.7 \pm 66$ & $29.9 \pm 6.4$ & $34.9 \pm 8.6$ & $37.2 \pm 6.6$ & $27.0 \pm 7.3$ & $24.1 \pm 8.6$ \\
$P_{0}$ & $85.8 \pm 18.2$ & $68.6 \pm 13.3$ & $62.9 \pm 4.5$ & $82.4 \pm 28^{*}$ & $62.5 \pm 12.4$ & $93.3 \pm 3.5^{*}$ & $56.6 \pm 17.7$ & $66.2 \pm 15.4$ \\
$P_{\mathrm{B}}$ & $-15.0 \pm 4.4$ & $-11.1 \pm 5.6$ & $-11.9 \pm 13.7$ & $-15.6 \pm 15.3$ & $-7.5 \pm 9.6$ & $-17.9 \pm 1.43^{*}$ & $-9.4 \pm 1.43$ & $-4.4 \pm 10.2$ \\
\hline
\end{tabular}

${ }^{*} P<0.05$ vs. control. HR, heart rate $(\mathrm{min}) ; d P / d t_{\max }$, maximum rate of use of $\mathrm{LV}$ pressure $(\mathrm{mmHg} / \mathrm{s}) ; d P / d t_{\min }$, maximum rate of fall of $L V$ pressure; $V_{\mathrm{ED}}, \mathrm{LV}$ end-diastolic volume $(\mathrm{ml}) ; V_{\mathrm{ES}}, \mathrm{LV}$ end-systolic volume $(\mathrm{ml}) ; P_{\mathrm{ED}}, \mathrm{LV}$ end-diastolic pressure $(\mathrm{mmHg}) ; P_{\mathrm{ES}}, \mathrm{LV}$ end-systolic pressure ( $\mathrm{mmHg}$ ); $t_{\max }$, time from end-diastole to end-systole (ms); $T$, time constant of the fall in $\mathrm{LV}$ pressure (ms); $P_{0}$ and $P_{\mathrm{B}}$, constants in the exponential model of fall of LV pressure (ms).

increase $E_{\max }$, they have different effects on $t_{\max }, T$, and the $d P / d t_{\max }-V_{\mathrm{ED}}$ relation. Dobutamine decreases $t_{\max }$, and $T$ and produces a greater increase in $d E / d t_{\max }$ (slope of $d P / d t_{\max }-V_{\mathrm{ED}}$ relation) than in $E_{\max }$. In contrast, ouabain does not alter $t_{\max }$ or $T$ and produces an equivalent increase in $d E / d t_{\max }$ and $E_{\max }$.

The effects of dobutamine and ouabain on peak elastance $\left(E_{\max }\right)$ and time from stimulation to occurrence of peak elastance $\left(t_{\max }\right)$ mirror their effects on the time-course of intracellular myocardial $\mathrm{Ca}^{2+}$ availability assessed using aequorin (13, 16). Dobutamine increases peak $\mathrm{Ca}^{2+}$ availability and $E_{\max }$ and decreases the time to achieve peak $\mathrm{Ca}^{2+}$ and $t_{\max }$. Ouabain increases peak $\mathrm{Ca}^{2+}$ and $E_{\max }$ without altering the time to peak
$\mathrm{Ca}^{2+}$ and $t_{\max }$. These similarities between the time-course of LV elastance and intracellular $\mathrm{Ca}^{2+}$ suggest that despite the complex geometry, LV chamber properties reflect the subcellular events underlying contraction $(14,15)$.

Both dobutamine and ouabain are positive inotropes that increase $E_{\max }$, thus shifting the $P_{\mathrm{ES}}-V_{\mathrm{ES}}$ relation to the left. Dobutamine produces no significant change in $V_{0}$, the volume intercept of the $P_{\mathrm{ES}}-V_{\mathrm{ES}}$ relation, while with ouabain, $V_{0}$ is decreased somewhat. This decrease in $V_{0}$ with ouabain is similar to the change in $V_{0}$ that has been observed in responses to vasoconstriction $(4,11,21,25)$. When the acute vasoconstrictive effect of ouabain is blunted by pretreatment with phentolamine, no decrease in $V_{0}$ was seen. Both ouabain and dobut-

Table II. Effect of Dobutamine and Ouabain on the $P_{E S^{-}} V_{E S}$ Relation

\begin{tabular}{|c|c|c|c|c|c|c|c|c|c|c|}
\hline & \multicolumn{5}{|c|}{ Control } & \multicolumn{5}{|c|}{ Dobutamine or ouabain } \\
\hline & No. & $\mathbf{R}$ & SEE & $E_{\max }$ & PVR VO & No. & $\mathbf{R}$ & SEE & $E_{\max }$ & PVR VO \\
\hline \multicolumn{11}{|c|}{ Effect of dobutamine } \\
\hline Mean & 29 & 0.986 & 1.99 & 7.24 & 12.42 & 22 & 0.978 & 3.11 & $13.61^{*}$ & 13.75 \\
\hline SD & 25 & 0.010 & 1.84 & 1.02 & 4.40 & 12 & 0.015 & 2.01 & 5.80 & 5.47 \\
\hline \multicolumn{11}{|c|}{ Effect of ouabain } \\
\hline Mean & 32 & 0.983 & 2.04 & 8.87 & 13.03 & 23 & 0.990 & 2.13 & $9.99^{*}$ & $10.61^{*}$ \\
\hline SD & 22 & 0.011 & 0.83 & 4.35 & 6.56 & 12 & 0.004 & 1.34 & 4.81 & 8.01 \\
\hline \multicolumn{11}{|c|}{ Effect of ouabain after beta-blockade } \\
\hline Mean & 33 & 0.985 & 1.51 & 6.65 & 12.51 & 30 & 0.971 & 2.70 & $8.61^{*}$ & $10.73^{*}$ \\
\hline SD & 17 & 0.008 & 0.52 & 1.47 & 5.60 & 13 & 0.019 & 1.02 & 2.19 & 6.07 \\
\hline \multicolumn{11}{|c|}{ Effect of ouabain after phentolamine } \\
\hline Mean & 56 & 0.986 & 2.01 & 8.19 & 11.23 & 41 & 0.976 & 2.67 & $11.71^{*}$ & 11.75 \\
\hline SD & 31 & 0.010 & 1.06 & 2.71 & 5.45 & 16 & 0.018 & 0.74 & 4.11 & 5.40 \\
\hline
\end{tabular}

* Different from control, $P<0.05$. No., number of points used in the regression of $P_{\mathrm{ES}}$ and $V_{\mathrm{ES}} ; \mathrm{R}$, correlation coefficient; SEE, standard error of the estimate $(\mathrm{mmHg}) ; E_{\max }$, slope of the $P_{\mathrm{ES}}-V_{\mathrm{ES}}$ relation $(\mathrm{mmHg} / \mathrm{ml})$; PVR VO, volume axis intercept of $P_{\mathrm{ES}}-V_{\mathrm{ES}}$ relation (ml). 
Table III. Effect of Ouabain and Dobutamine on the $d P / d t_{\max }-V_{E D}$ Relation

\begin{tabular}{|c|c|c|c|c|c|c|c|c|c|c|}
\hline & $\mathbf{R}$ & SEE & $d E / d t_{\max }$ & vo & $d E_{\mathbb{N}} / d t_{\mathbf{N}}$ & $\mathbf{R}$ & SEE & $d E / d t_{\max }$ & vo & $d E_{\mathrm{N}} / d t_{\mathrm{N}}$ \\
\hline \multicolumn{11}{|c|}{ Effect of Dobutamine } \\
\hline \multicolumn{6}{|c|}{ Control } & \multicolumn{5}{|c|}{ Dobutamine } \\
\hline Mean & 0.985 & 25 & 63.02 & 8.22 & 1.34 & 0.956 & 58.08 & $177.13^{*}$ & 10.90 & 2.38 \\
\hline SD & 0.013 & 10 & 20.38 & 2.63 & 0.65 & 0.045 & 48.87 & 83.60 & 5.55 & 0.94 \\
\hline \multicolumn{11}{|c|}{ Effect of ouabain } \\
\hline & \multicolumn{5}{|c|}{ Control } & \multicolumn{5}{|c|}{ Ouabain } \\
\hline Mean & 0.983 & 40 & 73.08 & 11.47 & 1.50 & 0.992 & 70.20 & $98.60^{*}$ & 11.31 & 1.68 \\
\hline SD & 0.019 & 29 & 30.68 & 3.04 & 0.33 & 0.005 & 75.95 & 47.88 & 6.10 & 0.34 \\
\hline \multicolumn{11}{|c|}{ Effect of ouabain after beta-blockade } \\
\hline & \multicolumn{5}{|c|}{ Beta-blocked } & \multicolumn{5}{|c|}{ Control } \\
\hline Mean & 0.968 & 35 & 60.11 & 7.50 & 1.71 & 0.954 & 54.86 & $93.84^{*}$ & 9.45 & 1.86 \\
\hline SD & 0.037 & 18 & 20.77 & 6.27 & 0.39 & 0.042 & 22.03 & 71.03 & 5.92 & 0.65 \\
\hline \multicolumn{11}{|c|}{ Effect of ouabain after phentolamine } \\
\hline & \multicolumn{5}{|c|}{ Phentolamine } & \multicolumn{5}{|c|}{ Ouabain } \\
\hline Mean & 0.987 & 41.12 & 119.08 & 9.09 & 2.19 & 0.983 & 56.88 & $177.05^{*}$ & 9.92 & 2.18 \\
\hline SD & 0.010 & 31.28 & 98.15 & 6.23 & 0.76 & 0.010 & 22.04 & 159.98 & 5.34 & 0.86 \\
\hline
\end{tabular}

* Different from control, $P<0.05$. $d E / d t_{\max }$, slope of the $d P / d t_{\max }-V_{\mathrm{ED}}$ relation (mmHg/s per ml); VO, volume axis intercept of the $d P / d t_{\max }$ $V_{\mathrm{ED}}$ relation $(\mathrm{ml}) ; d E_{\mathrm{N}} / d t_{\mathrm{N}},\left(d E / d t_{\max }\right)\left(t_{\max }\right) / E_{\max }$. Other abbreviations as in Table II.
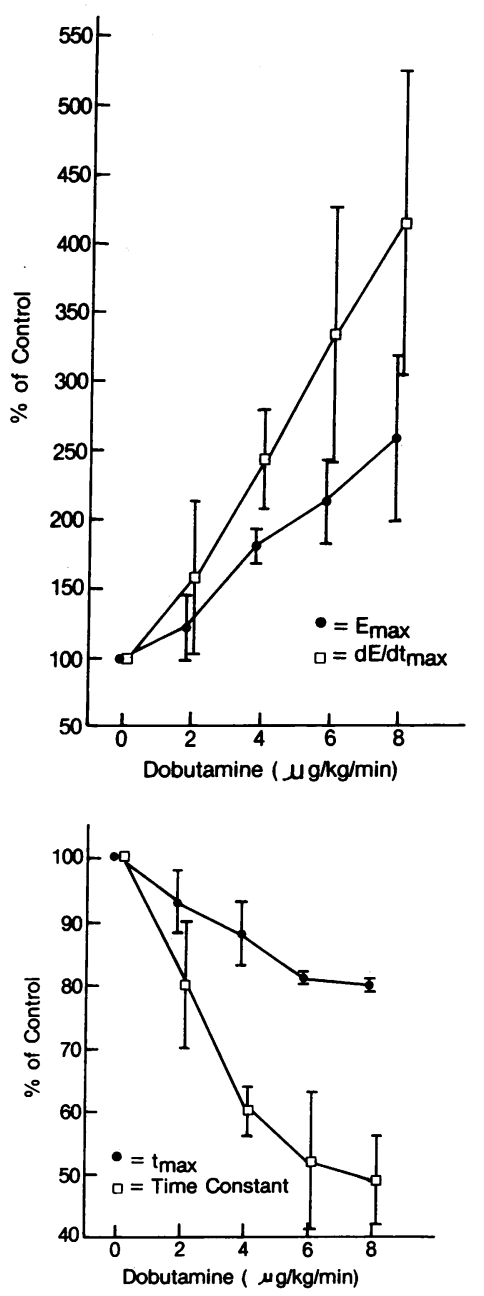

Figure 3. Responses of $E_{\max }, d E / d t_{\max }(A), t_{\max }$, and $T(B)$ to incremental infusions of dobutamine. $E_{\max }$ and $d E / d t_{\max }$ increase $(P<0.05)$, while $t_{\max }$ and $T$ decrease $(P<0.05)$ in response to dobutamine. Data are represented by mean \pm SD. amine increase the slope $\left(d E / d t_{\max }\right)$ of the $d P / d t_{\max }-V_{\mathrm{ED}}$ relation. The time-varying elastance model predicts that $d E / d t_{\max }$ is proportional to $E_{\max } / t_{\max }(3,4)$. Consistent with this prediction, dobutamine, which decreased $t_{\max }$, caused a greater increase in $d E / d t_{\max }$ than in $E_{\max }$, whereas ouabain, which did not change $t_{\max }$, produced an equivalent increase in $E_{\max }$ and $d E / d t_{\max }$. Our previous study, which demonstrated that catecholamine administration produced a greater increase in $d E$ / $d t_{\max }$ than in $E_{\max }$, suggested that the $d P / d t_{\max }-V_{E D}$ relation may be more sensitive to inotropic state than the $P_{\mathrm{ES}}-V_{\mathrm{ES}}$ relation (4). However, this present study indicates, consistent with the prediction of the time-varying elastance model, that this is true only for inotropic interventions that decrease $t_{\max }$, and not for interventions such as digitalis administration that do not alter $t_{\max }$.

We found that dobutamine and ouabain have different effects on isovolumic relaxation. Because relaxation is an active process, isovolumic relaxation can be considered part of systole (1). During this period LV pressure declines exponentially $(1,15,26-28)$. Thus, the rate of fall of LV pressure can be

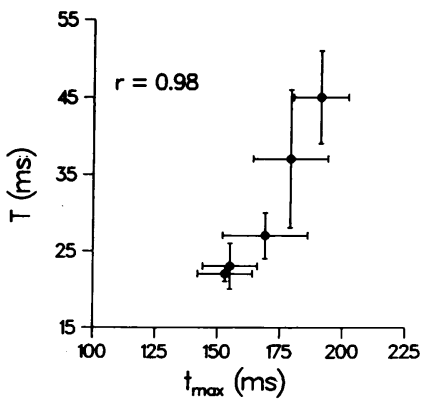

Figure 4. Both $T$ and $t_{\max }$ increase during the incremental infusion of dobutamine. The mean values are linearly related $(r=0.98)$. 

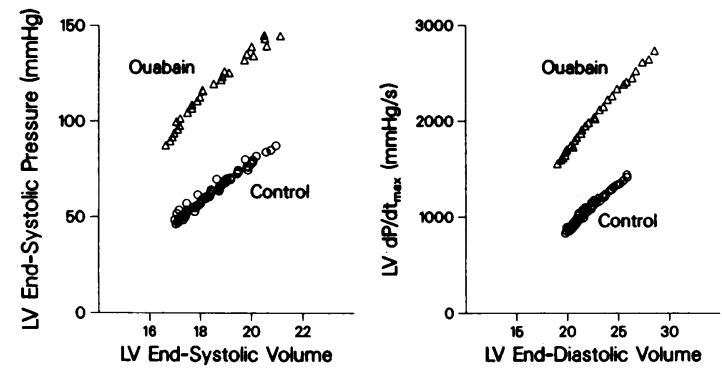

Figure 5. Ouabain shifts both the left ventricular end-systolic pressure-volume and $d P / d t_{\max }$-end-diastolic volume relations to the left with comparable increases in the slope of both relations.

quantified using the time constant $(T)$ of the pressure fall. We assessed the rate of pressure fall using an exponential model including a pressure asymptote. It has been shown that $T$ can be substantially altered by changes in loading conditions, most markedly the afterload $(28,29)$. In addition, $T$ is also influenced by the rate of contractile inactivation (1). Most positive inotropic interventions such as catecholamine administration decrease $T$, whereas negative inotropic interventions such as ischemia increase $T$. This has led to the concept that inotropic state is a determinant of the rate of isovolumic relaxation $(30,31)$. The current study and observations in isolated cardiac muscle (32) are not consistent with this hypothesis. We found that ouabain, a positive inotrope, increased $E_{\max }$ and $d E / d t_{\max }$, but did not alter $t_{\max }$ or $T$. Ouabain's lack of effect on $T$ was not altered by pretreatment with propanolol or phentolamine given to blunt the hypertensive response to acute ouabain administration. Thus, ouabain's lack of influence on $T$, does not appear to result from changes in afterload. These results are consistent with the observations of Weiss et al. (26) that another digitalis compound, acetylstrophanthidin, did not alter $T$ in isovolumic, isolated canine hearts. We found that dobutamine, which also increases $E_{\max }$ and $d E / d t_{\max }$, decreases $t_{\max }$ and $T$. The decrease in $T$ with incremental infusions of dobutamine parallels the decrease in $t_{\max }$. These findings suggest that the positive inotropic response that increases $E_{\max }$ and $d E / d t_{\max }$ can be separated from the response that speeds the rate of activation $\left(t_{\max }\right)$ and relaxation $(T)$. These observations of the possible relation between changes in $t_{\max }$ and $T$ are consistent with a prediction of the time-varying elastance hypothesis as derived in Appendix.

The differences in the effects of inotropic agents on isovolumic relaxation may have clinical importance. Catecholamines, such as dobutamine, that speed relaxation may help improve early diastolic filling of the LV, whereas digitalis would not.

Since our results are consistent with the predictions of the time-varying elastance model concerning the $P_{\mathrm{ES}}-V_{\mathrm{ES}}$ relation and its links to the $d P / d t_{\max }-V_{\mathrm{ED}}$ relation and to $T$, our study supports the use of time-varying elastance as a conceptual framework to understand and link events occurring during isovolumic systole $\left(d P / d t_{\max }-V_{\mathrm{ED}}\right.$ relation), at end-systole $\left(P_{\mathrm{ES}}-\right.$ $V_{\mathrm{ES}}$ relation) and isovolumic relaxation $(T)$. During these parts of systole there is little or no change in LV volume. It is important to recognize that the simple time-varying elastance model may not provide an accurate description of the LV during ejection when $L V$ volume is rapidly changing $(21,33)$.

In conclusion, this study shows that although dobutamine and ouabain are both positive inotropes that increase $E_{\max }$, dobutamine speeds the rate of LV contraction $\left(t_{\max }\right)$ and isovolumic relaxation $(T)$, whereas ouabain does not. These effects of ouabain and dobutamine on global parameters of LV chamber performance mirror their influences on intracellular calcium availability. Furthermore, our observations are consistent with the predictions of the time-varying elastance model of the LV and support its usefulness as a conceptual framework to understand and link the events occurring during isovolumic contraction, at end-systole, and during isovolumic relaxation.
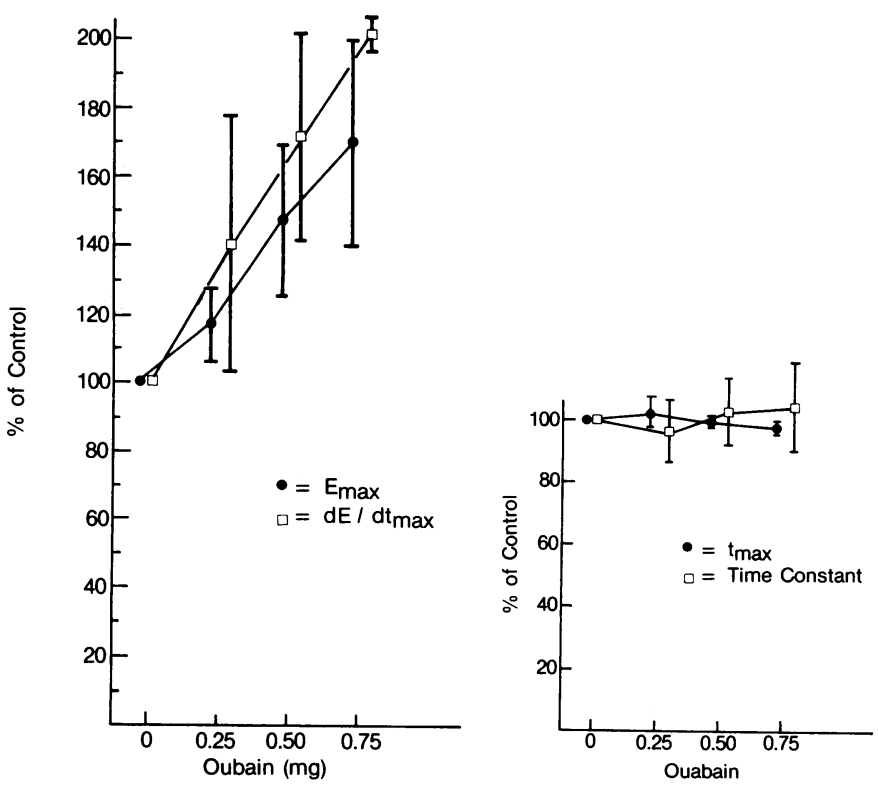

Figure 6. Response of $E_{\max }, d E / d t_{\max }(A), t_{\max }$, and $T$ $(B)$ to a range of doses of ouabain. $E_{\max }$ and $d E / d t_{\max }$ increase $(P<0.05)$ while $t_{\max }$ and $T$ are unchanged in response to ouabain. Data are represented by mean \pm SD 


\section{Appendix}

The time-varying elastance model holds that:

$P(t)=E(t)\left[V(t)-V_{0}\right]$.

Furthermore, $E(t)$ can be characterized by $E_{\max }, t_{\max }$, and $E_{\mathrm{N}}\left(t / t_{\max }\right)$, as:

$E(t)=E_{\max } E_{\mathrm{N}}\left(t / t_{\max }\right)$.

$E_{\mathrm{N}}\left(t / t_{\max }\right)$ is a normalized elastance function independent of loading and inotropic state from end-diastole to end-systole, but during isovolumic relaxation there is some variation in $E_{\mathrm{N}}$ that is probably due to changes in loading conditions and the history of the preceding contraction (2). During isovolumic relaxation $V(t)=V_{\mathrm{EE}}$, the end-ejection volume; thus Eq. 1 reduces to:

$P(t)=E(t)\left[V_{\mathrm{EE}}-V_{0}\right]$.

Because $P(t)$ falls exponentially during isovolumic systole it can be described as:

$P(t)=P_{0} \mathrm{e}^{-t / T}+P_{\mathrm{B}}$,

where $T$ is the time constant of $L V$ pressure decline, $P_{\mathrm{B}}$ is the residual pressure after complete relaxation and $\left(P_{0}+P_{\mathrm{B}}\right)$ is the initial pressure at which the exponential decline begins. Using Eqs. 3 and 4, this results in the following relation during isovolumic relaxation:

$E(t)=E_{0} \mathrm{e}^{-t / T}+E_{\mathrm{B}}$,

where $E_{0}=P_{0} /\left(V_{\mathrm{EE}}-V_{0}\right)$ and $E_{\mathrm{B}}=P_{\mathrm{B}} /\left(V_{\mathrm{EE}}-V_{0}\right)$. Combining Eqs. 2 and 5 and rearranging results in:

$E_{\mathrm{N}}\left(t_{\mathrm{N}}\right)=\left(E_{0} / E_{\max }\right) \mathrm{e}^{-\left(t_{\mathrm{N} / \max } / T\right)}+\left(E_{\mathrm{B}} / E_{\max }\right)$,

where $t_{\mathrm{N}}$ is $t / t_{\max }$. Thus, $T_{\mathrm{N}}$, the time constant of the decline in normalized elastance, is given by:

$T_{\mathrm{N}}=T / t_{\max }$

Rearranging gives:

$T=t_{\max } T_{\mathrm{N}}$.

Thus, the time-varying elastance hypothesis predicts that the time constant of the fall in LV pressure during isovolumic relaxation $(T)$ is proportional to $t_{\max }$, the time from end-diastole to end-systole, and $T_{\mathrm{N}}$, the time constant of the decline of normalized elastance.

\section{Acknowledgments}

We gratefully acknowledge the skilled technical assistance of Che-Ping Cheng, James Colston, Danny Escobedo, James Galloway, Brad Trott, and Don Watkins, and the expert word processing of Joye Zafuto.

This work was supported in part by National Institutes of Health (1-R01-HL37324), a grant-in-aid from American Heart Association with funds contributed in part by the Texas affiliate, and the Veterans Administration. Dr. Little is an Established Investigator of the American Heart Association.

\section{References}

1. Brutsaert, D. L., F. E. Rademakers, and S. U. Sys. 1984. Triple control of relaxation: implications in cardiac disease. Circulation. 69:190-196.

2. Suga, H., and K. Sagawa. 1974. Instantaneous pressure-volume relationships and the excised supported canine left ventricle. Circ. Res. 35:117-128.

3. Sunagawa, K., and K. Sagawa. 1982. Models of ventricular contraction based on time-varying elastance. CRC Crit. Rev. Biomed. Eng. 7:193-228.
4. Little, W. C. 1985. The left ventricular $\mathrm{dP} / \mathrm{dt}_{\max }$-end-diastolic volume relation in closed-chest dogs. Circ. Res. 56:808-815.

5. Weber, K. T., J. S. Janicki, W. C. Hunter, S. Schroff, E. S. Pearlman, and A. P. Fishman. 1982. The contractile behavior of the heart and its functional coupling to the circulation. Prog. Cardiovasc. Dis. 24:375-400.

6. Suga, H., K. Sagawa, and A. A. Shoukas. 1973. Load independence of the instantaneous pressure-volume ratio of the canine left ventricle and effects of epinephrine and heart rate on the ratio. Circ. Res. 32:314-322.

7. Suga, H., and K. Yamakoshi. 1977. Effects of stroke volume and velocity of ejection on end-systolic pressure of canine left ventricle. Circ. Res. 40:445-450.

8. Suga, H., A. Kitabatake, and K. Sagawa. 1979. End-systolic pressure determines stroke volume from fixed end-diastolic volume in the isolated canine left ventricle. Circ. Res. 44:238-249.

9. Sagawa, K. 1978. The left ventricular pressure-volume diagram revisited. Circ. Res. 43:677-687.

10. Sagawa, K. 1981. The end-systolic pressure-volume relation of the ventricle: definition, modification and clinical use. Circulation. 63:1223-1227.

11. Sodums, M. T., F. R. Badke, M. R. Starling, W. C. Little, and R. A. O'Rourke. 1984. Evaluation of left ventricular contractile performance utilizing end-systolic pressure-volume relationships in conscious dogs. Circ. Res. 54:731-739.

12. Grossman, W., E. Braunwald, T. Mann, L. P. McLaurin, and L. W. Green. 1977. Contractile state of the left ventricle in man as evaluated from end-systolic pressure-volume relations. Circulation. 56:845-852.

13. Morgan, J. P., J. H. Cheseboro, J. R. Pluth, F. J. Puga, and H. V. Schaff. 1984. Intracellular calcium transients in human working myocardium as detected with aequorin. J. Am. Coll. Cardiol. 3:410418.

14. Freeman, G. L., J. W. Covell, R. L. Engler, and M. M. LeWinter. 1985. Relationship between local myocardial fiber direction and segmental shortening. Circ. Res. 56:31-39.

15. Brutsaert, D. L., P. R. Housemans, and M. A. Goethals. 1980. Dual control of relaxation: its role in the ventricular function in the mammalian heart. Circ. Res. 47:637-652.

16. Morgan, J. P., and K. G. Morgan. 1984. Calcium and cardiovascular function: intracellular calcium levels during contraction and relaxation of mammalian cardiac and vascular smooth muscle as detected with aequorin. Am. J. Med. 5:33-46.

17. Little, W. C., F. R. Badke, and R. A. O'Rourke. 1984. Effect of right ventricular pressure on the left ventricular diastolic pressure-volume relationship in dogs without pericardia. Circ. Res. 54:718-730.

18. Little, W. C., and R. A. O'Rourke. 1985. Effect of regional ischemia on the left ventricular end-systolic pressure-volume relation in chronically instrumented dogs. J. Am. Coll. Cardiol. 5:297-302.

19. Slinker, B. K., and S. A. Glantz. 1985. The accuracy of inferring left ventricular volume from dimensions depends on the frequency of the information needed to answer a given question. Circ. Res. 56:161174.

20. Park, R. C., W. C. Little, and R. A. O'Rourke. 1985. Effect of alterations of the left ventricular activation sequence on the left ventricular end-systolic pressure-volume relation in closed-chest dogs. Circ. Res. 57:706-717.

21. Little, W. C., and G. L. Freeman. 1986. Evaluation of the load dependence of ventricular time-varying elastance in closed-chest dogs. Fed. Proc. 45:1130. (Abstr.)

22. Olsen, C. O., G. S. Tyson, G. W. Maier, J. A. Spratt, J. W. David, and J. S. Rankin. 1983. Dynamic ventricular interaction in the conscious dog. Circ. Res. 52:85-104.

23. Dixon, W. J., M. B. Brown, L. Entleman, J. W. Frane, M. A. Hill, R. I. Jennich, and J. D. Toporek. 1983. BMDP Statistical Software. University of California Press, Berkeley, CA. 237-250. 
24. Glantz, S. A. 1981. Primer of Biostatistics. McGraw-Hill, New York.

25. Maughan, W. L., K. Sunagawa, D. Burkhoff, and K. Sagawa. 1984. Effect of arterial impedance changes on the end-systolic pressure-volume relation. Circ. Res. 54:595-602.

26. Weiss, J. L., J. W. Frederiksen, and M. L. Weisfeldt. 1976. Hemodynamic determinants of the time-course of fall in canine left ventricular pressure. J. Clin. Invest. 58:751-760.

27. Thompson, D. S., C. B. Waldron, D. J. Coltart, B. S. Jenkins, and M. M. Webb-Peploe. 1982. Estimation of time constant of left ventricular relaxation. Br. Heart J. 49:250-258.

28. Raff, G. L., and S. A. Glantz. 1981. Volume loading slows left ventricular isovolumic relaxation rate: evidence of load-dependent relaxation in the intact dog heart. Circ. Res. 48:813-824.

29. Gaasch, W. H., J. D. Carroll, A. S. Blaustein, and O. H. L. Bing.
1986. Myocardial relaxation: effects on the time-course of isovolumetric relaxation. Circulation. 73:1037-1041.

30. Cohn, P. F., A. J. Liedtke, J. Serur, E. H. Sonnenblick, and C. W. Urschel. 1972. Maximal rate of pressure fall (peak negative $\mathrm{dP} / \mathrm{dt}$ ) during ventricular relaxation. Cardiovasc. Res. 6:263-267.

31. Karliner, J. S., M. M. LeWinter, F. Mahler, R. Engler, and R. A. O'Rourke. 1977. Pharmacologic and hemodynamic influences on the rate of isovolumic left ventricular relaxation in the normal conscious dog. J. Clin. Invest. 60:511-521.

32. Parmley, W. W., and E. H. Sonnenblick. 1969. Relation between mechanics of contraction and relaxation in mammalian cardiac muscle. Am. J. Physiol. 216:1084-1091.

33. Schroff, S. G., J. S. Janicki, and K. T. Weber. 1985. Evidence and quantitation of left ventricular systolic resistance. Am. J. Physiol. 249:H358-H370. 